\title{
Biomolecular Interaction and Photohemolytic Effect of Gold Nanoparticles
}

\author{
Poorani $^{1 *}$, Aruna Prakasa Rao ${ }^{1}$, Ganesan Singaravelu ${ }^{1}$ and Elanchezhiyan Manickam ${ }^{2}$ \\ ${ }^{1}$ Department of Medical Physics, Anna University, India \\ ${ }^{2}$ Department of Medical Microbiology, Madras University, India
}

Submission: December 18, 2016; Published: January 10, 2017

*Corresponding author: Poorani Gananathan, Department of Medical Physics, Anna University, Chennai, India, Email: poorani.nss@gmail.com

\section{Abstract}

The interaction between colloidal gold nanoparticles with bovine serum albumin, hemoglobin and Deoxy Ribo Nucleic acid were studied by spectroscopy. The conjugation of proteins with NPs not only affords stabilization of the system but, more importantly, also introduces biocompatible functionalities into nanoparticles for further biological interactions. The surface modifications of gold nanoparticles to provide stable bimolecular functionalized NPs in biomedical applications have been reported. Next, photo hemolytic activity of gold nanoparticles and light photons in hematocrit were studied.

Photo induced hemolysis is a colloidal-osmotic process due to loss of selective permeability of the photo damaged membrane leads to indiscriminate entrance of solute molecules, swelling and eventual membrane rupture. $30 \mathrm{~nm}$ gold nanoparticles were synthesized by reduction technique using trisodium citrate and the size was confirmed by Transmission electron Microscopy and UV-Visible absorption spectroscopy. $0.05 \%$ hematocrit treated with gold nanoparticles and irradiated with Nd: YAG II harmonic laser with $532 \mathrm{~nm}$. Percentage hemolysis, lipid peroxidation by melanaldehyde assay, protein estimation by Lowry's method and intracellular GSH assay by Ellmans's method were studied. During hemolysis protein get released, lack of peroxides and comparative GSH rate was observed. And also, rate of hemolysis were calculated by varying the fluency and GNP dose. Hemolysis and lipid peroxidation studies confirm that GNPs involved in hemolysis without peroxidation and release of proteins.

\section{Introduction}

There has been a burgeoning increase in the utilization of nanomaterials for several applications including the treatment of cancer. The nanoparticles are discrete particles that have a diameter of $100 \mathrm{~nm}$ or less; larger than individual atoms and molecules but are smaller than bulk solid [1]. Gold when confined to nanosize, gives surface dominance leading to absorption, fluorescence, elastic and Raman scattering properties. For gold nanoparticles, these optical properties render both bright contrast agents for imaging and highly effective tools for cellular and tissue level therapeutics. The absorption cross-section of these nanoparticles orders of magnitude stronger than the strongest absorbing molecules and the scattered light is $10^{5}$ times more intense than the fluorescence of organic dyes and the nanoparticles do not photobleach [2].

The surface of gold nanoparticles (GNPs) can be modified by a wide variety of small molecules, such as peptides, proteins, DNA and polymers [3]. The efficacy of nanoparticle, biodistribution and their interaction with other compounds are highly affected by their binding nature and interaction with proteins. Proteins adsorb to the particle surface strongly, hence stabilization is afforded by the large positive free energy of desorption to avoid aggregation. The protein coated gold colloids retain their native structure without denaturation which allows further application of those bio functionalised nanoparticles. Bovine serum albumin (MW: 67,000 D) is widely used in biological studies as a molecular carrier for the conjugation of fluorescent markers, peptides and protein fragments and nanoparticles. Serum albumin is the basic protein of blood plasma, consisting of 580 amino acids residues involved in transport of substances poorly soluble in water, including drugs such as sulfonamides, aspirin, and penicillin. Albumin can also associates nanoscale particles, promoting their transport through cells.

Gold nanoparticles used for phototherapeutic application need to be functionalized with biocompatible materials to avoid toxicity, enhance the binding and penetration into cells. The interaction of nanoparticles with biomolecules helps to understand the mechanism in vitro studies since BSA, DNA and $\mathrm{Hb}$ are vital biomolecules involved in transport of substances. 
The activity of nanomaterial inside the cells mainly based on the proteins. The nanomaterials must be compatible to nucleic acids since these are genetic materials are critical when undergo changes. Blood the carrier of drugs and nanomaterials add the advantage when the GNP bound to the hemoglobin easily.

Based on the importance of all the three biomolecules interaction study of gold nanoparticles with them is significant before the application of GNPs for in vitro studies. GNPs are considered to be an alternative photo sensitiser due its efficient bioconjucation, potential non-cytotoxicity, tunable and enhanced scattering, absorption and fluorescent properties and easy preparation. However, there is no detailed study on the synthesis, characterization and Photodynamic Activity (PDA) of gold nanoparticles. Erythrocytes treated with $30 \mathrm{~nm}$ GNPs and green light of $530 \mathrm{~nm}$ wavelengths. The mechanism of photosensitized hemolysis was revealed by evaluating red blood cell membrane structural transformations, parameters of hemolysis, rates of cellular glutathione oxidation, Protein estimation and membrane lipid peroxidation. This was achieved by irradiation and post irradiation treatment conditions on the courses of hemolysis.

\section{Materials and Methods}

\section{Interaction of BSA, DNA and hemoglobin with gold nanoparticles}

$\mathrm{HAuCl}_{4}$ from CRL, Trichloro acetic acid, 5,5,9-dithiobis (2-nitrobenzoic acid) (Ellman's reagent), 2-thiobarbituric acid (TBA) and trichloroacetic acid (TCA) were from Sigma-Aldrich, Germany; dimethyl sulfoxide was from Sigma, St. Louis, MO, USA. Blood from healthy donors were collected from the Health centre, Anna University, Chennai. In this method, different sizes of GNPs ranging from $3 \mathrm{~nm}$ to $76 \mathrm{~nm}$ were synthesized by changing the concentration of Trisodium Citrate (TSC), the duration of heating and stirring processes. TSC reduces only at temperatures above $80^{\circ} \mathrm{C}$ and acts as a capping agent at this temperature as well. The UV - Vis absorption spectra were obtained for the synthesized gold nanospheres in the wavelength regime of 400-800 $\mathrm{nm}$. The effect of concentration of the reducing agent, TSC on the normalized absorption spectra are shown in Figure 1. The concentration of TSC is inversely proportional to the size of the nanoparticle. As the size of the formed gold nanospheres increase, a red shift is observed in the UV-Vis absorption spectra.

To study the interaction of BSA with gold nanoparticles the 2 $\mu \mathrm{M}$ BSA was prepared. The solution was allowed to interact with different size and concentration of gold nanoparticles and the interaction was studied by absorption and fluorescence studies. Here $2 \mu \mathrm{M}$ BSA was prepared by using phosphate buffer saline $\left(\mathrm{p}^{\mathrm{H}}\right.$-7.4) and mixed with different size of gold nanoparticles for their absorption studies. Also $0.02 \mu \mathrm{M}$ BSA was prepared and mixed with different concentration of gold nanoparticles for fluorescent studies. $20 \mu \mathrm{M}$ solution of BSA was prepared and the $\mathrm{p}^{\mathrm{H}}$ was found to be 7.2. Previously the same experiment was tried with BSA of $0.2 \mu \mathrm{M}, 0.02 \mu \mathrm{M}, 2 \mu \mathrm{M}$ and $20 \mu \mathrm{M}$ concentration. $2 \mu \mathrm{M}$ and $20 \mu \mathrm{M}$ concentration was considered to be suitable for interaction studies. Before carrying out the experiment, the nanoparticle concentration was matched with the concentration of $20 \mu \mathrm{M}$ BSA by matching the optical density of absorption spectra by UV-Vis spectroscopy. To study the interaction of nanoparticle with BSA the experiments were carried out by using 3 different size of nanoparticles with varying concentration.

BSA was incubated with 3 different sizes for 2 hrs. After the incubation period, each sample was read using UV spectra for measuring its absorbing regions. Similarly the fluorescence characterization was also examined for gold nanoparticles. To study the interaction of haemoglobin with gold nanoparticles the $4 \mu \mathrm{M}$ hemoglobin was prepared. The solution was allowed to interact with different concentrations of gold nanoparticles and the interaction was studied by absorption and fluorescence studies. Hemoglobin powder with a molecular weight of 68,000 daltons $(68,000 \mathrm{~g}$ per mole $)$ stored at a temperature of $2-30^{\circ} \mathrm{C}$ was used and $\mathrm{pH}$ maintained at 7.4. Interaction studies were carried out with different size and concentration of gold nanoparticles meant for absorption and fluorescence studies. For DNA interaction with gold nanoparticle studies, the $\mathrm{p}^{\mathrm{H}}$ was maintained at 7.4. The concentration of DNA solution was determined from UV absorption at $260 \mathrm{~nm}$ using a molar extinction coefficient $6000 \mathrm{M}^{-1} \mathrm{~cm}^{-1}$.

$$
\begin{aligned}
& A=\varepsilon c l \\
& C=A / \varepsilon l .
\end{aligned}
$$

$2 \mathrm{ml}$ of DNA was allowed to mix with $500 \mu \mathrm{l}$ of GNP, incubated for 2 hours. After incubation absorption were recorded for the complex in the wavelength range from 200-800 nm. Interaction of DNA with GNPs studied with fluorescence studies. DNA having weak fluorescence, bind to ethidium bromide and the mixture was used for interaction assay with GNPs. For fluorescence studies DNA in Tris $\mathrm{HCl}$ mixed with ethidium bromide in a 3:1 ratio to perform the fluorescence intercalator displacement assay.

\section{Photohemolysis}

Blood samples were collected from volunteers in EDTA coated vacutainers. For photohemolysis assay, heamatocrit prepared by washing them three times with a phosphate-buffered saline solution (PBS) of $\mathrm{p}^{\mathrm{H}} 7.4$ (0.01 M phosphate buffer and $0.135 \mathrm{M}$ $\mathrm{NaCI}$ ), each time centrifuging the cells at 1500 for $5 \mathrm{~min}$ and carefully removing the supernatant and buffy coat. Diluting $2 \mathrm{ml}$ of RBC with $38 \mathrm{ml}$ PBS and further diluted $4 \mathrm{ml}$ of first dilution sample to $36 \mathrm{ml}$ of PBS prepared $0.05 \%$ haematocrit. The resultant suspension had an optical density (OD) of 0.40 .8 at $650 \mathrm{~nm}$. An OD value of 0.5 corresponded to $3.3 \times 10^{6} \mathrm{cell} / \mathrm{ml}$, read with ELISA reader. Blood samples $(0.05 \%$ hematocrit $)$ were taken for the binding study of the cells with nanoparticles, shown with the help of hemolysis curves taken with variation in concentration of nanoparticle and time of exposure. The absorption peak of gold 
nanoparticles $(530 \mathrm{~nm})$ matches with the incident wavelength of light. The irradiated samples at different concentration of nanoparticles were read at $413 \mathrm{~nm}$ the absorption maxima of heme. From the concent ratio based curve, maximum hemolysis was observed for the $200 \mu$ l concentration of gold nanoparticles irrespective of the optical dose. This was also found to be the same for various exposure times. Maximum hemolysis was observed in 5 minutes exposure. There is exponential decline after a particular concentration. This may be due to shielding effect or by the self absorption of nanoparticle itself.

This is found for $1 \mathrm{ml}$ of nanoparticles in which number of nanoparticles absorbs the light from the source and dissipates the rest of energy between them and hence the energy will not reach the erythrocytes. Hemolysis study was carried out to optimize the concentration of nanoparticles and energy. Gold nanospheres were irradiated using green light with $530 \mathrm{~nm}$ wavelength and 34 $\mathrm{mW}$ power for 15 mins providing energy of $30 \mathrm{~J}$. Hemolysis rate was $70-85 \%$ for the concentration ranging from $10 \mu \mathrm{l}$ to $50 \mu \mathrm{l}$. Rate of hemolysis found to be independent of concentration. The irradiated samples at different concentration of nanoparticles were read at $413 \mathrm{~nm}$ and the dose was calculated. The percent hemolysis as the function of optical dose was calculated. It is observed that the percent hemolysis increases very rapidly at a given dose of $38 \mathrm{~J} / \mathrm{cm}^{2}$ and it attains saturation for dose upto $190 \mathrm{~J} / \mathrm{cm}^{2}$. Above this dose, the percent hemolysis decreases with optical dose. There is exponential decline after a particular concentration. The decrease in the percentage hemolysis at dose above $190 \mathrm{~J} / \mathrm{cm}^{2}$ is may be considered due shielding effect or by the self-absorption of nanoparticle.

Photorradiated hematocrit samples were estimated by the method developed by Lowry et al., The basic principle is that the peptide bond (-CO-NH-) in the polypeptide chain reacts with copper sulfate in the alkaline medium to give a blue colored complex. In addition, tyrosine and tryptophan residues of protein cause the reduction of the phosphomolybdate and phosphotungstate components of the Folin Ciocalteau's reagent to give a bluish products, which contribute towards enhancing the sensitivity of the method.The peroxidation of lipid was estimated using accumulation of malondialdehyde (MDA). Lipid peroxidation: malondialdehyde (MDA), the final product of fatty acid peroxidation, reacts with Thiobarbituric acid.

The level of TBARS was measured on the basis of absorbance at the wavelength of $535 \mathrm{~nm}$. The concentration of malondialdehyde was quantified by UV-Vis Spectrophotometer. The accumulated MDA is measured spectroscopically using 2-thiobarbituric acid. The GSH level was determined by the method of Ellman's et al. Briefly, $0.2 \mathrm{ml}$ of $25 \%$ TCA was added to $2 \mathrm{ml}$ of final RBC suspension and centrifuged. To $1 \mathrm{ml}$ of the supernatant, $1 \mathrm{ml}$ of 1 M phosphate buffer $\left(p^{\mathrm{H}} 7.4\right)$ and 0.1 ml Ellman's reagent $\left(10^{23} \mathrm{M}\right)$ were added for GSH determination. Concentration of GSH was monitored at $412 \mathrm{~nm}$ using the extinction coefficient $13.6 \mathrm{mM}$.

\section{Results and Discussion}

Gold nanospheres which showed absorption spectra in the region between of 500-580 $\mathrm{nm}$. A pronounced feature of nanoscale particles of noble metals is the surface plasmon resonance (SPR) band in the visible region of the absorption spectrum. A high efficiency of excitation of surface plasm on waves (SPWs) on the gold nanoparticle surface allows their use in the development of biosensors [4] and in medical photothermal therapy [5]. In this study the absorption maxima for the nanoparticle was observed in $530 \mathrm{~nm}$. The figure indicates the absorption spectra of gold nanoparticle. The detailed study of BSA interaction with GNP is necessary since its most important biological function is to carry drugs, endogenous and exogenous substances.

The shift in the absorption peak of nanoparticles shows very narrow changes till $20 \mathrm{~nm}$ since the SPR is not well defined below $20 \mathrm{~nm}$ GNPs. For the spheres from $20 \mathrm{~nm}$ to $80 \mathrm{~nm}$ in diameter, the wavelength shift ranges from $520-580 \mathrm{~nm}$ based on the Surface Plasmon Resonance (SPR) of the GNPs. The concentration and the dispersion of the GNPs are determined by the peak intensity and the (Full Width Half Maximum) FWHM respectively. Thus from the spectra it is inferred that the GNPs synthesized thus are mono disperse. Different size of particles ranging from $15 \mathrm{~nm}$ to $76 \mathrm{~nm}$ has been synthesized by varying the concentration of trisodium citrate (Figure 1). Depending on the size of GNPs the absorption wavelength varies. As the size increases, a red shift in the absorption spectra was observed. Variation in the concentration of the particle is indicated with varying intensities in the UV-Vis absorption spectra. From the UV - Vis absorption study it is highly confirmed that the synthesized particles are nanoparticles and our results highly correlates with the reported work of Wolfgang Haiss et al. [5] (Table 1).In the present study, necessary relations were obtained from the obtained data to determine size of nanoparticle using UV-Vis absorption spectra. A graph (Figure 1) indicates the dependence of size over wavelength and the dependence of size over concentration. The results are correlated with the results of El Sayed et al. [6] particle size was determined by theoretical method and the formula is

Table 1: Gold Nanoparticle size calculated from absorption spectra.

\begin{tabular}{|c|c|c|c|c|}
\hline $\begin{array}{c}\text { TSC } \\
\mathbf{( 0 . 3 4 M )} \text { ill }\end{array}$ & iLmax & $\begin{array}{c}\text { Particle } \\
\text { size (nm) }\end{array}$ & El Sayed & $\begin{array}{c}\text { Particle } \\
\text { size (nm) }\end{array}$ \\
\hline 50 & 546 & 76 & 545 & 80 \\
\hline 100 & 539 & 66 & 540 & 60 \\
\hline 150 & 537 & 62 & 535 & 50 \\
\hline 200 & 534 & 56 & 530 & 40 \\
\hline 250 & 527 & 39 & 525 & 30 \\
\hline 300 & 525 & 32 & & \\
\hline
\end{tabular}




\section{International Journal of Cell Science \& Molecular Biology}

$$
\text { Particle size }=\ln \left(\left(\lambda_{\max }-\lambda_{520}\right) / 6.53\right) /(2 \times 0.0216)
$$

The as-such prepared nanoparticles have a $\mathrm{p}^{\mathrm{H}}$ of 6.8 . Hence the particles can be used for further biological applications without surface modification. In biological solutions, GNPs tend to be fairly unstable and aggregate therefore losing their important properties. In this regard, it is pertinent to have complete knowledge about the stability of particles in various $\mathrm{p}^{\mathrm{H}}$ environments [6]. Figure shows the UV- Vis absorption spectra of GNPs with BSA (concentration of $2 \mu \mathrm{M}$ ) after 2 and 24 hours of incubation. The $\mathrm{pH}$ values of both the BSA solution and colloidal GNPs should be adjusted to slightly above the isoelectric point of the BSA before the interaction study is performed [7]. This allows an effective electrostatic binding of the cationic amino acid side chains of the protein with the anionic citrate groups on the colloids. Steric stabilization is offered by the proteins attached to the GNPs. More importantly, unlike the adsorption on the flat gold surfaces, the proteins coated on gold colloids retain their native structure without denaturation, which allows further application of those bio-modified nanoparticles [8]. The spectra were normalized at their peak absorption wavelengths for both the protein and GNPs. From the Figure 1, it is observed that the spectral signature for protein shows increase in absorption intensity and no shift in the wavelength. This enhancement was due to absorption of BSA which is present partly on the surface of GNP [7]. The change in the intensity of the absorption peak at 280nm explicitly shows the formation of surface complex [9]. However, there is a considerable variation in the peak absorption position of GNPs with respect to particle size. The smaller size nanoparticles exhibit higher red shift (bathochromic shift) and it is maximum for $3 \mathrm{~nm}$ gold nanoparticles (Figure 2).

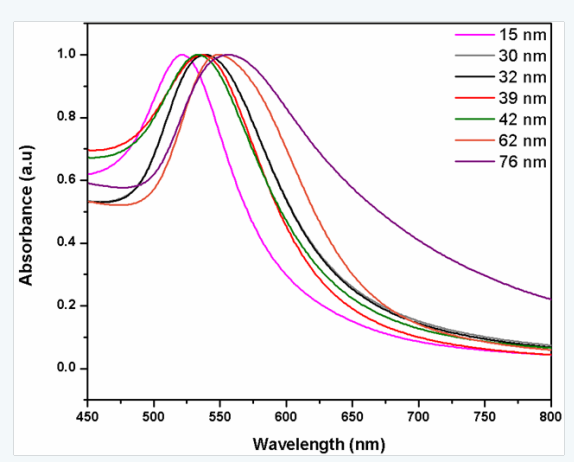

Figure 1: Normalized UV-Vis absorption spectra of gold nanospheres.

The interaction between gold and those molecules can be noncovalent electrostatic interaction, hydrophobic interaction or covalent binding [10]. The GNPs are negatively charged due to the citrate layer, and protein or protein conjugates could bind electro statically to the GNP surface through positively charged amino acid side chains. Red shift in absorption maxima of GNP is due to the folding of proteins (Figure 2). The correlation between size of the gold nanoparticle and the Plasmon frequency observed remains linear, except at stages where protein folding intermediates are formed [11]. Higher particle size with less red shift cannot be easily explained unless one assumes the specific protein dependant self assembly of such particles. If a protein template is present, the reducing environment is altered. Amino groups or exposed thiol groups present on a peptide surface can offer an environment that may facilitate emergence of size stabilized particles. Again, exposed tyrosins may aid the reduction process, where an electron from the tyrosinate ion of the peptide is transferred to the metal ion at basic $\mathrm{p}^{\mathrm{H}}$ through the formation of a tyrosyl radical, converted to dityrosine form during the reaction. GNPs have large surface area and less surface charge, therefore, BSA-Nanosphere complex can be formed more easily resulting larger binding constant for BSA nanosphere [12].

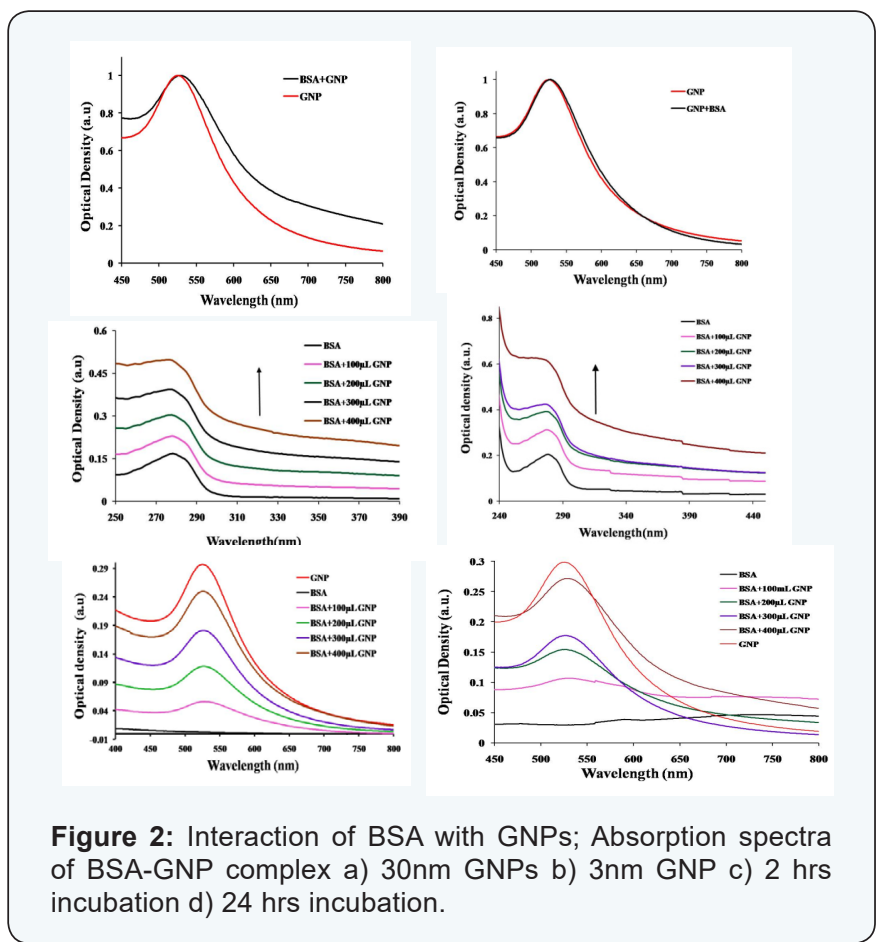

After 24 hours of interaction with BSA, it is observed from the absorption spectra that the particles agglomerate (Figure 2). The spectral overlapping in the protein region, indicates the BSA are not bound to the nanoparticles' surface. The GNP absorption region shows, spectral broadening and the subsequent absence of peak as the concentration of GNP decreases. The dependence of the plasmon band position on the degree of aggregation of the nanoparticles and on the dielectric constant of the local environment forms the basis for chemical sensing with gold nanoparticles. The presence of chemical or biological analytes can induce aggregation, disaggregation, or change the local refractive index, which accordingly results in change of the plasmon band position. This can be attributed to (Figure 2) high localization of plasma oscillations of the electric field, the plasmon oscillation parameter can change only at very close contact of a nanoparticles and BSA molecules [13]. By this, the GNP-BSA association was confirmed. Our results match with Drude model for protein interaction study. Hemoglobin was allowed to interact with GNPs of different concentration. After incubation period of $2 \mathrm{~h}$ the samples were read using UV-Vis 
spectrophotometer and their corresponding absorption spectra were recorded. The absorption of both the hemoglobin and GNP before and after interaction were analysed. In the absoprtion spectra no shift was observed in $406 \mathrm{~nm}$ which corresponds to the absorption maxima of hemoglobin. In case of GNPs, $2 \mathrm{~nm}$ shift was observed which is a bathochromic shift. Shift in absoprtion spectra of GNPs shows that, there is interaction of GNPs with hemoglobin [14] which need further studies for detailed understanding behind the mechanism of interaction.The GNPs absorbance spectra lies in the range between 500-600 nm.

The spectra (Figure 2) clearly shows there occurs a slight broadening in the absorption spectrum of the GNPs as the concentration, as the hemoglobin increases and there is no shift in the absorption maxima. A high efficiency of excitation of surface plasmon waves (SPWs) on the GNPs surface allows their use in the development of biosensors [15] and in medical photothermal therapy [16]. The fluorescence spectra of a protein is usually studied with the fluorescing amino acids Tryptophan or Tyrosine in our study. The protein was excited at $280 \mathrm{~nm}$ and the emission spectra was recorded from $300 \mathrm{~nm}$ to $550 \mathrm{~nm}$. Hemoglobin does not have fluorescence due to the presence of metal ion, hence the fluorescence was recorded by exciting the complex at $280 \mathrm{~nm}$ which is a the fluorescence of globin the fluorescence for hemoglobin-GNPs florescence intensity for low concentration of GNPs is shown in Figure 4. It was observed that the fluorescence intensity decreases in the GNP, this might be due to the size of the particles, surface charge etc which can be determined by further studies. The decrease in the intensity of fluorescence intensity confirms that the GNP has interacted with hemoglobin. The Figure 3 indicates the fluorescence spectra for the interaction of GNPs with hemoglobin.
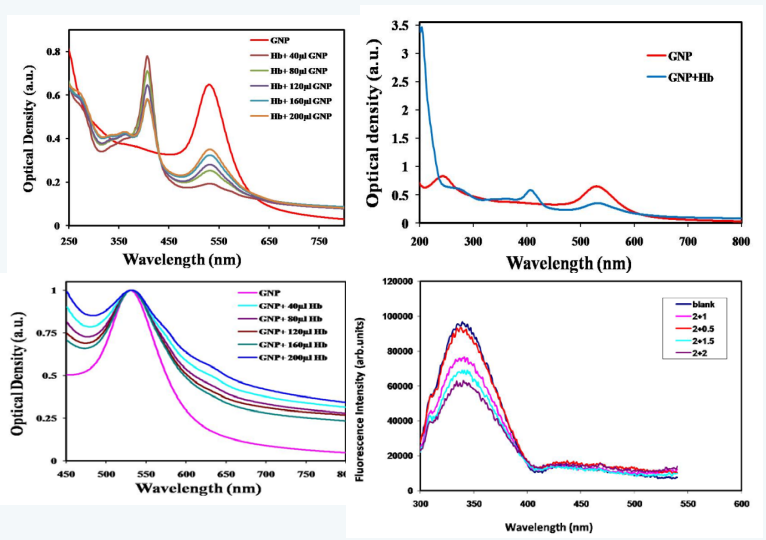

Figure 3: UV-Vis Absorption Spectra of Hb-GNP complex a) $\mathrm{Hb}$ absorption increases with increasing concentration of GNPs b) Spectra of Hb-GNP complex. Figure UV-Vis absorption spectra of spectral broadening of Hb-GNP complex with different concentration of $\mathrm{Hb}$.

Changes in emission spectra of Tryptophan emisssion spectra are common in response to protein conformational transitions, subunit association, substrate binding or denaturation. Thus the intrinsic fluorescence of protein can provide considerable information about their structure and dynamics and is often considered in the study of protein folding and association reactions [17]. From the table and table, it is observed that the peak absorption and emission varies for different size of GNPs. Red shift was observed for GNP in the case of UV-Vis absorption spectra in Figure 3 and was reversed for fluorescence emission in Figure 3. In this context further studies are required to know about the nature of interaction and reasons of the altered spectral characteristics. The hemoglobin molecule is an assembly of four globular protein subunits. Each subunit is composed of a protein chain tightly associated with a non-protein heme group. A heme group consists of an iron (Fe) ion (charged atom) held in a heterocyclic ring, known as a porphyrin. The iron ion, which is the site of oxygen binding, bonds with the four nitrogens in the center of the ring, which all lie in one plane. The iron is also bound strongly to the globular protein via the imidazole ring of the histidine residue below the porphyrin ring. A sixth position can reversibly bind oxygen, completing the octahedral group of six ligands. Oxygen binds in an "end-on bent" geometry where one oxygen atom binds $\mathrm{Fe}$ and the other protrudes at an angle. When oxygen is not bound, a very weakly bonded water molecule fills the site, forming a distorted octahedron.

\section{Gold Nanoparticles with DNA}

The commercial CT-DNA was tested for its protein contamination by UV spectra. UV absorbance at 260 and $280 \mathrm{~nm}$ was obtained, A260/280 of 1.89 indicating that the DNA was sufficiently free of protein. The absorption spectrum of DNA was shown in the Figure. The maximum absorption wavelength of DNA is $260 \mathrm{~nm}$ which is due to the chemical properties of the nucleotide bases. Resonance among the atoms in the ring structure of purines and pyrimidines gives most of bonds partial double-bond character. As a result of resonance all the nucleotide bases absorb UV light, and nucleic acids are characterized by a strong absorption wavelength near 260nm. After incubation of DNA with GNPs the samples were read using in UV- Vis spectrophotometer for measuring the absorption spectra. UV-Vis absorption spectra of DNA in the presence of varying amounts of GNPs were shown in the Figure 4. The changes in DNA - was observed between $230 \mathrm{~nm}$ to $300 \mathrm{~nm}$. No appreciable shift in the maximum wavelength of DNA was observed in Figure 4. But there is decrease in the intensity of absorbance of DNA due to GNP complex.

The absorption spectra of GNP are shown in Figure 4. In this experiment the GNPS are found to have absorption in the region of 500-600nm, 2 different size of GNPs were used. Difference in the maximum absorption wavelength was observed between these two GNPs due to variation in particle size. Similarly the absorption spectra varied and showed red shift for increase in particle size. The UV-Vis absorption spectra of GNPss in the presence and absence of DNA was observed in the region between 400 to $800 \mathrm{~nm}$ shown in the Figure 4. Compared to GNPs sample, the GNP-DNA complex showed a shift in wavelength. A red shift of 8nm (hypsochromism) was observed. 
The term hypsochromism signifies that the absorption intensity of a sample is less than the sum of its constituent parts, which implies that hypochromism reflects a structural interaction [13] at $480 \mathrm{~nm}$. Fluorescence quenching of Hemoglobin with different concentration of GNPs excited at $280 \mathrm{~nm}$.
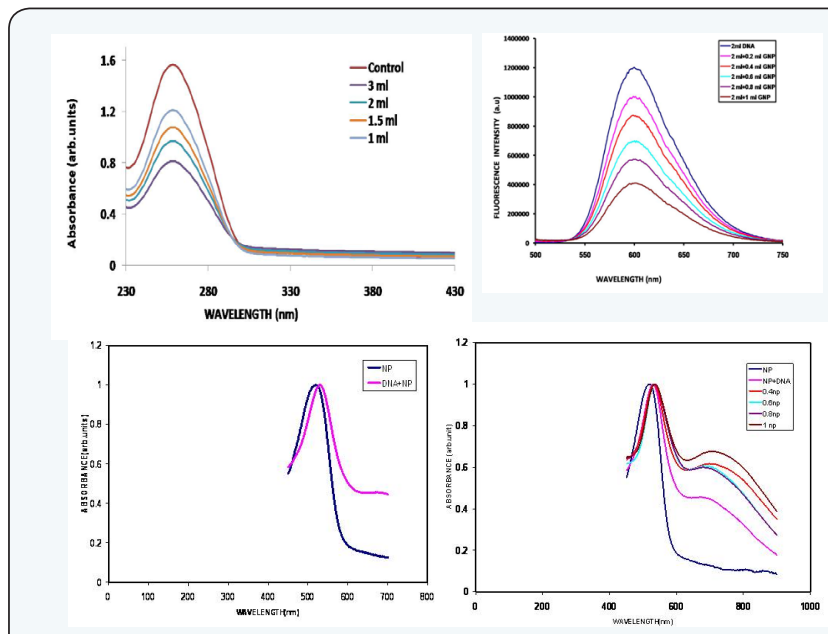

Figure 4: UV-Vis absorption spectra of DNA Eb complex with different concentration of GNP Normalised UV-Vis absorption spectra of DNA-GNP complex a) Fluorescence Emission spectra of DNA-Eb with different concentration of GNP excited at $480 \mathrm{~nm}$. Fluorescence quenching of Hemoglobin with different concentration of GNPs excited at $280 \mathrm{~nm}$.

As DNA itself does not have fluorescing property, the fluorescence characteristics for DNA-GNP complex interaction were studied using ethidium bromide. Ethidium bromide an intercalator of DNA displays very weak fluorescence in aqueous solution. However in the presence of DNA it exhibits intense fluorescence because of the intercalation to base pair in DNA. So DNA was mixed with ethidium bromide in 3:1 ratio to observe the fluorescence of EtBr directly corresponds to the activity of DNA. The complex was excited at $480 \mathrm{~nm}$, which is the absorbance maxima of ethidium bromide, and the emission was recorded from $500 \mathrm{~nm}-750 \mathrm{~nm}$. Ethidium bromide emits intense fluorescence light in the presence of DNA, due to its strong intercalation between the adjacent DNA base pairs. It is reported that the enhanced fluorescence can be quenched by the addition of a second molecule. The quenching extent of fluorescence of ethidium bromide bound to DNA is used to determine the extent of binding between the second molecule and DNA. Figure shows the decrease in fluorescence intensity when GNP was added to the ethidium bromide-DNA complex. As the concentration of GNP increases, decrease in fluorescence intensity of DNA-Ethidium bromide complex was observed. This may be due of the addition of GNP which compete with the hydrophobic intercalator, ethidium bromide, for DNA binding sites either directly (via intercalative insertion) or indirectly, by promoting a DNA conformation incompatible with ethidium bromide-binding. Removal of the intercalator in a concentrationdependent manner provided a binding curve for the GNP. As GNP by itself lack fluorescing property, the decreasing fluorescence is not due to light absorption or by interference due to the particles [18]. Thus the quenching in the fluorescence Ethidium bromide by GNPs may imply the interaction between the GNP and DNA (Figure 5).

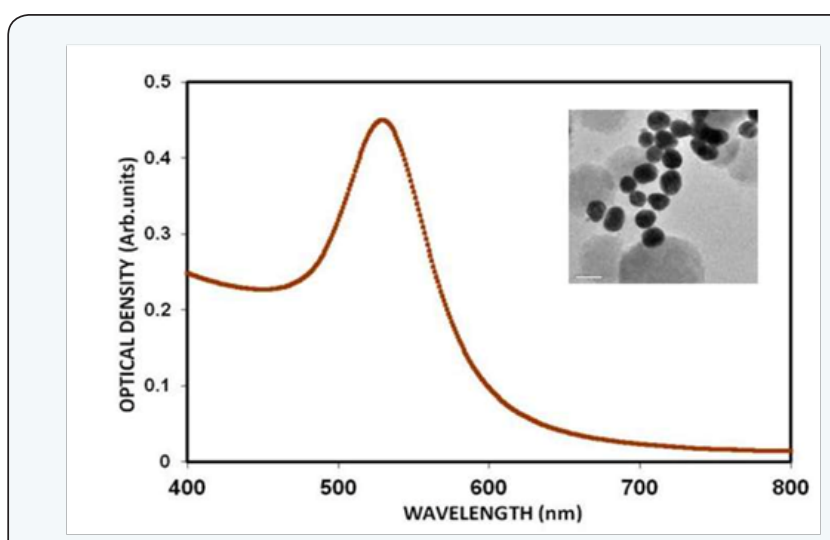

Figure 5: Absorption spectra of gold nanoparticles, Inlet: TEM image of gold nanoparticles.

The primary objective of the study is to determine oxidative stress that induces hemolysis in Erythrocytes. In general, the ensuing photochemical reaction is dependent on the presence of oxygen, it generates reactive oxygen species (ROS) and induces oxidative stress in the cells, what means destruction of cells [19]. ROS react with thiol groups of proteins and cause damage of cellular membranes. Oxidative stress causes damage to cellular macromolecules, such as nucleic acids, proteins and lipids. Among these targets, peroxidation of lipids is particularly more damaging because the formation of lipid peroxidation products leads to a facile propagation of free radical, malondialdehyde (MDA) - an endogenous genotoxic compound.The crucial factors, which determine the type of cell death, include light dose, the sensitivity of cells and the concentration of photosensitizer [20]. The concentration varied from 5 to $1000 \mu$ l. doesnot show much variation in the rate of hemolysis from 5 to $300 \mu \mathrm{l}$. For $500 \mu \mathrm{l}$ hemolysis reduced to $30 \%$ and $12 \%$ for $1000 \mu \mathrm{l}$. Which may be due to shielding effect. For further studies nanoparticles of concentration from 10-50 $\mu$ l were used where the rate of hemolysis reached $80 \%$.The energy was varied from $5 \mathrm{~J}$ to 30 J by varying irradiation time from 3 mins to 15 mins. Maximum hemolysis found for $30 \mathrm{~J}$ and this power was used for further studies.

We suggest that irradiation for $15 \mathrm{~min}$ and $50 \mu \mathrm{l}$ for red blood cells give optimized The higher concentration of gold nanoparticles produces shielding effect in cells. Oxidative stress damage that affects hemolytic is also dependent on incubation time with photosensitizing agent before and after exposure to light [2]. We maintain one hour incubation before irradiation and biomolecular assays were carried out immediately after irradiation. For finding the mode of hemolysis the protein estimation was carried out. Our studies revealed that protein content increased after hemolysis may be due to membrane damage or loss of selective permeability (Figure 6). 


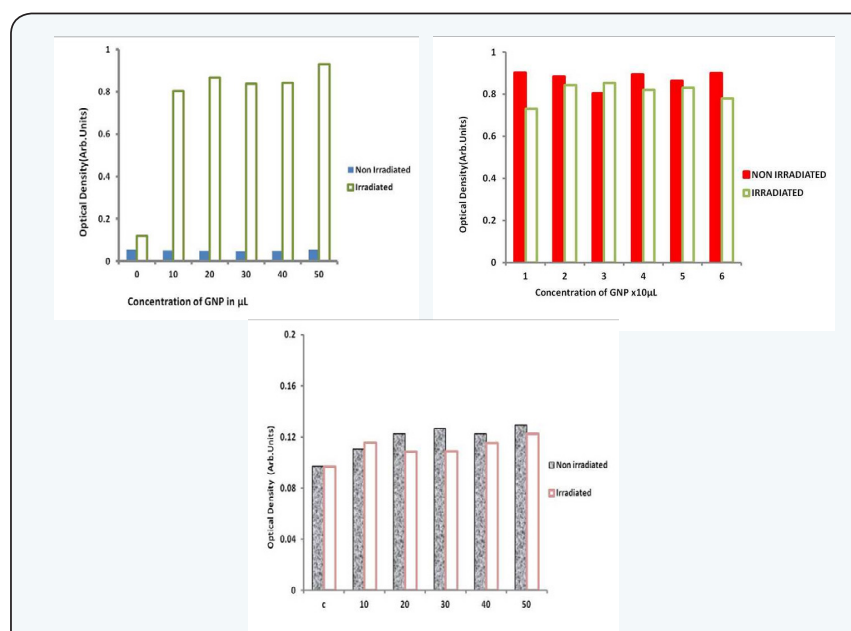

Figure 6: Protein Estimation, Lipid peroxidation and GSH assay of gold nanoparticles.

Examining proteins of erythrocytes with gold nanoparticles before and after irradiation, a distinct increase of protein was observed [10] which may be due to release of hemoglobin from ruptured erythrocytes and membrane proteins or may be due to the loss of membrane permeability. GSH assay shows GSH does not play any role in photohemolysis reactions since the level of GSH in irradiated and non irradiated cells were similar to that of control. To confirm the role of membrane protein in hemolysis we need further studies. The levels of the malonyldialdehyde product of lipid peroxide oxidation in blood cells, treated by green light, depending on the time and photosensitizer concentration. Lipid peroxidation was not found and that was an indication of an absence of reactive oxygen species in the environment. The size of the particle determines its mode of entry into the cell. The nanoparticle needs a biocompatible surface to enter the cell by passive mechanism. This biocompatible surface is provided by BSA when it replaces Trisodium Citrate attaching to the surface of the gold nanoparticle. The interaction between colloidal gold nanoparticles of various sizes was studied with BSA using absorption and fluorescence spectral measurements.

\section{Conclusion}

Gold nanoparticles can be used as drug vector and the nanoparticle bound to hemoglobin in erythrocytes is a potential drug carrier. In targeted area, upon irradation these nanoparticles act as suicide bombers to kill the cancer cells.

\section{References}

1. Mironava T, Hadjiargyrou M, Simon M, Jurukovski V, Rafailovich $M H$ (2010) Gold nanoparticles cellular toxicity and recovery: effect of size, concentration and exposure time. Nanotoxicology 4(1): 120-137.

2. Pitsillides CM, Joe EK, Wei X, Anderson RR, Lin CP (2003) Selective cell targeting with light-absorbing microparticles and nanoparticles. Biophys J 84(6): 4023-4032.

3. Homola J, Yee SS, Gauglitz G (1999) Surface plasmon resonance sensors: review. Sensors and Actuators B: Chemical 54(1): 3-15.
4. Pissuwan D, Niidome T, Cortie MB (2011) The forthcoming applications of gold nanoparticles in drug and gene delivery systems. J Control Release 149(1): 65-71.

5. Wolfgang Haiss, Thanh NT, Jenny Aveyard, David G Fernig (2007) Determination of Size and Concentration of Gold Nanoparticles from UV-Vis Spectra. Anal Chem 79(11): 4215-4221.

6. Jain PK, Lee KS, El-Sayed IH, El-Sayed MA (2006) Calculated absorption and scattering properties of gold nanoparticles of different size, shape, and composition: applications in biological imaging and biomedicine. J Phys Chem B 110(14): 7238-7248.

7. Jianping Xie, Yuangang Zheng, Jackie Y Ying (2009) Protein-Directed Synthesis of Highly Fluorescent Gold Nanoclusters. J Am Chem Soc 131(3): 888-889.

8. Bifeng Pan, Daxiang Cui, Yuan Sheng, Cengiz Ozkan, Feng Gao, et al. (2007) Dendrimer-Modified Magnetic Nanoparticles Enhance Efficiency of Gene Delivery System. Cancer Res 67(17): 8156-8163.

9. Thi Ha Lien Nghiem, Thi Huyen La, Xuan Hoa Vu, Viet Ha Chu, Thanh Hai Nguyen, et al. (2010) Synthesis, capping and binding of colloidal gold nanoparticles to proteins. Adv Nat Sci: Nanosci Nanotechnol 1(2).

10. Weibo Cai, Ting Gao, Hao Hong, Jiangtao Sun (2008) Applications of gold nanoparticles in cancer nanotechnology. Nanotechnol Sci Appl 2008(1).

11. Tapan K Sau, Anjali Pal, Jana NR, Wang ZL, Tarasankar Pal (2001) Size controlled synthesis of gold nanoparticles using photochemically prepared seed particles. Kluwer Academic Publishers, Journal of Nanoparticle Research, Netherlands 3(4): 257-261.

12. Catherine J Murphy, Anand M Gole, John W Stone, Patrick N Sisco, Alaaldin M Alkilany, et al. (2008) Gold Nanoparticles in Biology: Beyond Toxicity to Cellular Imaging. Acc Chem Res 41(12): pp 17211730.

13. Ilya B Zavodnika, Leu B Zavodnika, Maria J Bryszewskab (2002) The mechanism of Zn-phthalocyanine photosensitized lysis of human erythrocytes J Photochem Photobiol B 67(1): 1-10.

14. Franklin Vargas, Ingert Martinez Volkmar, Julio Sequera, Hisbeth Mendez, Jenny Rojas, et al. (1998) Photodegradation and phototoxicity studies of furosemide. Involvement of singlet oxygen in the photoinduced hemolysis and lipid peroxidation. J Photochem Photobiol B 42(3): 219-225.

15. Vladimir Chekulayev, Igor Shevchuk, Lyudmila Chekulayeva, Anne Kahru (1997) Study of the photochemical and phototoxic properties of lonidamine [1-(2,4-dichlorobenzyl) -1H-indazol-3-carboxylic acid]. Journal of Photochemistry and Photobiology B: Biology 41(1-2): 1121.

16. Shevchuk IN, Chekulayev VA, Chekulayeva LV (2002) The role of lipid peroxidation and protein degradation in the photodestruction of ehrlich ascites carcinoma cells sensitized by hematopororphirin derivative. Experimental oncology 24: 216-224.

17. Roczniki Akademii Medycznej w Bialymstoku (2004) Proceedings Annales Academiae Medicae Bialostocensis 49.

18. Wei-Lung Tseng, Kun-Hong Lee, Huan Tsung Chang (2005) Using Nile Red-Adsorbed Gold Nanoparticles To Locate Glutathione within Erythrocytes. Langmuir 21(23): 10676-10683.

19. Nishima Wangoo, Bhasin KK, Mehtab SK, Raman Suri C (2008) Synthesis and capping of water-dispersed gold nanoparticles by an amino acid: Bioconjugation and binding studies. J Colloid Interface Sci 323(2): 247-254.

20. Dakrong Pissuwan, Stella M Valenzuela, Michael B Cortie (2006) Therapeutic possibilities of plasmonically heated gold nanoparticles. Trends Biotechnol 24(2): 62-67. 
This work is licensed under Creative Commons Attribution 4.0 Licens DOI: 10.19080/IJCSMB.2017.01.555567
Your next submission with Juniper Publishers will reach you the below assets

- Quality Editorial service

- Swift Peer Review

- Reprints availability

- E-prints Service

- Manuscript Podcast for convenient understanding

- Global attainment for your research

- Manuscript accessibility in different formats ( Pdf, E-pub, Full Text, Audio)

- Unceasing customer service

Track the below URL for one-step submission https://juniperpublishers.com/online-submission.php 